\title{
Oral Squamous Cell Carcinoma on Gingiva, Edentulous Ridge, and Retromolar Pad: A Case Series
}

\author{
Lucio Lo Russo ${ }^{1, *}$, Eleonora Lo Muzio ${ }^{2}$, Giuseppe Colella ${ }^{3}$, Maria Eleonora Bizzoca ${ }^{1}$, , Vera Panzarella ${ }^{4}$, \\ Giuseppina Campisi ${ }^{4}$ and Lorenzo Lo Muzio ${ }^{1}$ (D)
}

1 Department of Clinical and Experimental Medicine, University of Foggia, 71121 Foggia, Italy; marielebizzoca@gmail.com (M.E.B.); lorenzo.lomuzio@unifg.it (L.L.M.)

2 School of Dentistry, University of Ferrara, 44122 Ferrara, Italy; eleonoralomuzio@gmail.com

3 Multidisciplinary Department of Medical-Surgical and Odontostomatological Specialties, University of Campania, “Luigi Vanvitelli", 80138 Naples, Italy; giuseppe.colella@unicampania.it

4 Department of Surgical, Oncological and Oral Sciences, University of Palermo, 90128 Palermo, Italy; panzarella@odonto.unipa.it (V.P.); campisi@odonto.unipa.it (G.C.)

* Correspondence: lucio.lorusso@unifg.it

check for updates

Citation: Lo Russo, L.; Lo Muzio, E.; Colella, G.; Bizzoca, M.E.; Panzarella, V.; Campisi, G.; Lo Muzio, L. Oral Squamous Cell Carcinoma on Gingiva, Edentulous Ridge, and Retromolar Pad: A Case Series. Oral 2021, 1, 159-167. https://doi.org/ 10.3390 /oral1020016

Academic Editors: Omar Kujan and Johannes H. Schmitz

Received: 30 March 2021

Accepted: 15 June 2021

Published: 18 June 2021

Publisher's Note: MDPI stays neutral with regard to jurisdictional claims in published maps and institutional affiliations.

Copyright: (c) 2021 by the authors. Licensee MDPI, Basel, Switzerland. This article is an open access article distributed under the terms and conditions of the Creative Commons Attribution (CC BY) license (https:// creativecommons.org/licenses/by/ $4.0 /)$.

\begin{abstract}
Background: Gingival cancer has a significant incidence and is often diagnosed at advanced stages. The aim of this paper is to highlight its clinical aspects on the basis of a case series analysis in order to promote awareness and improve the diagnosis process. (2) Methods: Oral cancers diagnosed and treated at three Italian University Hospitals over ten years were retrospectively investigated. Cancer location on the gingiva, edentulous ridge, and retromolar pad was addressed. Data regarding clinical features, stage at the diagnosis, and time from presenting symptoms to first medical consultation were retrieved. (3) Results: Thirty-three cancers located on the gingiva, edentulous ridge, and retromolar pad were retrieved from 276 total oral cancer cases (11.9\%). A median of 50 days (range 2-300) passed for the patient to seek for a medical evaluation. At the time of diagnosis, $63.3 \%$ were advanced stage cancers, mainly located at the mandible (91\%), especially in the retromolar pad $(48.5 \%)$ and the edentulous alveolar ridge $(24.2 \%)$. Lesions were red $(45.5 \%)$, red and white $(45.4 \%)$, or white $(9.1 \%)$, appearing as an ulcer $(69.7 \%)$, exophytic mass $(12.1 \%)$ or flat lesion (12.1\%). Sixty-six percent of cancers were completely asymptomatic, regardless their clinical appearance. A statistically significant association between the time from the presentation of symptoms to the first medical consultation and the cancers stage was found. (4) Conclusions: The clinical appearance of gingival cancer is very polymorphous; its understanding may be significant to improve patient education and early medical consultation.
\end{abstract}

Keywords: oral cancer; gingiva; diagnosis; clinical appearance

\section{Introduction}

Age standardized rates (per 100,000) for the incidence and deaths caused by lip and oral cavity cancers have been estimated as high as four and two, respectively [1]. Oral squamous cell carcinoma (OSCC) is the most frequent oral malignant tumor ( $90 \%$ of all oral cancers).

Males are more affected than females (overall male to female ratio $=2: 1$ ) $[2,3]$; the highest incidence occurs between 50 and 70 years of age, although a disproportional increase of incidence in a younger age group (younger than 45 years old) has been reported [4].

Survival and quality of life of OSCC patients remain very disappointing. In fact, the five-year survival rate for oral cavity and oropharynx cancers are approximately $50 \%$ in Europe and are expected to be even lower in developing countries [5].

Diagnostic delay can be still identified as a major cause of such a high mortality [6]. In fact, the majority (two-thirds) of OSCCs are still diagnosed at an advanced stage [7] when the current standard of care (surgery and radiotherapy) may fail in controlling the 
primary disease, as well as loco-regional and/or distant metastases. Hence, early diagnosis is mandatory in order to reduce oral cancer burden, improve clinical outcomes and tremendously reduce treatment-related morbidity. In addition, given the rising incidence and the variations in incidence by subsites across global regions and countries, there is a need for tailored approaches to prevention, screening, and treatment interventions [3].

The gingiva is a common location of oral cancer, reported as the third [8] most common subsite for OSCC. The prevalence of OSCC in gingival locations ranges from about 10\% [9] up to a quarter [10] of all oral cancers, although wide age and regional variations exist [11] The gingival location of OSCC may have several implications. In fact, anatomical reasons may facilitate local invasiveness to bone. On the other hand, clinical examination of the gingiva is frequently performed in a professional setting as part of dental and periodontal diseases prevention, treatment and/or maintenance programs, thus offering a great opportunity to identify lesions at a very early stage, even before the beginning of symptoms. A thorough understanding of clinical aspects of gingival cancer by all professionals involved in oral health management may reduce oral cancer diagnostic delay and misdiagnosis. In fact, although gingival cancer can sometimes mimic tooth-related benign inflammatory conditions (dento-alveolar abscess [12], endodontic-periodontic lesions [13], other benign lesions [14], or periodontal diseases [15]), a careful examination is a key factor for a correct and timely differential diagnosis.

In the present paper, data regarding clinical aspects of OSCC on the gingiva, the stage at the diagnosis and time passed for the patient to seek for the first medical consultation were addressed based on a case series analysis.

\section{Materials and Methods}

A ten-year retrospective evaluation of data from OSCC cases diagnosed and treated at three Italian University Hospitals (Hospital of the Campania University of Naples, University of Palermo, and University of Foggia) was performed. OSCC cases located on the gingiva, edentulous ridge, or retromolar pad were included in this study, and the following information retrieved from patients' medical records: age, gender, symptoms at the time of the first examination, time from patient awareness of the lesion/symptoms to the first medical consultation (patient delay), site of the primary lesion, history of medical examinations, macroscopic aspects of the lesion, exposure to risk factors, staging and grading, nodal involvement, treatment performed, and distant metastases. The clinical stage was established according to the cancer staging manual of the American Joint Committee on Cancer [16].

The clinical classification of the cases was also performed according to their macroscopic appearance and taking into account the following main aspects of the lesions, with the corresponding categories reported in parentheses: (i) color (white, red, red and white); and (ii) morphology (flat lesion, ulcer, exophytic mass, mixed lesion). In addition, the following descriptors were used for additional features: (i) margins of lesions (consistency: indurated, soft; outline: well-defined, ill-defined; profile: elevated, not elevated); and (ii) surface characteristics (homogeneous, non-homogeneous, verrucous).

The potential association between patient delay and the stage at the diagnosis was investigated by means of an $\chi^{2}$ test with a 0.05 significance level (H0: no association), using a statistical software program (jamovi; https:/ / www.jamovi.org, accessed on 10 March 2021). To this end the patient delay was transformed into an ordinal four classes variable according to the following strategy; class $1:<15$ days, class 2: between 16 and 30 days; class 3: between 31 and 60 days; class $4:>60$ days.

\section{Results}

Thirty-three cases of OSCC located on the gingiva, edentulous ridge, or retromolar area were retrieved from 276 total OSCC cases. In all cases, OSCC diagnosis was based on histopathological examination. Twenty-one were males (mean age: 57 years; range: 19-79) and 12 were female (mean age: 61 years; range: $25-86$ ). With regard to the most common 
oral cancer risk factors, eight patients were smokers, equally distributed in both genders. There was also one former smoker, seven patients admitted alcohol consumption, and one was a former alcohol user.

More than half of the cases $(63.6 \%)$ were advanced stage cancers (stage III and IV) (Table 1). The distribution of the cancers according to the T score was: 17 (51.5\%) T4 (in particular, these were T4a cancers invading through cortical bone of the jaws), $12(36.4 \%)$ $\mathrm{T} 1,3(9 \%) \mathrm{T} 2$, and one (3\%) T3.

Table 1. Site distribution and TNM parameters for the investigated OSCC lesions.

\begin{tabular}{|c|c|c|c|c|c|c|c|c|}
\hline & \multirow{2}{*}{ Stage } & \multirow{2}{*}{$\begin{array}{l}\text { Number of } \\
\text { Cases }\end{array}$} & \multirow{2}{*}{$\begin{array}{l}\% \text { of Total } \\
\text { Cases }\end{array}$} & \multicolumn{2}{|c|}{ Maxilla } & \multicolumn{3}{|c|}{ Mandible } \\
\hline & & & & Gingiva & $\begin{array}{l}\text { Edentulous } \\
\text { Ridge }\end{array}$ & Gingiva & $\begin{array}{l}\text { Edentulous } \\
\text { Ridge }\end{array}$ & $\begin{array}{c}\text { Retromolar } \\
\text { Pad }\end{array}$ \\
\hline \multirow[t]{4}{*}{ Clinical stage } & $\mathrm{I}$ & 7 & $21.2 \%$ & 0 & 0 & 2 & 1 & 4 \\
\hline & II & 5 & $15.2 \%$ & 0 & 0 & 2 & 2 & 1 \\
\hline & III & 4 & $12.1 \%$ & 1 & 0 & 0 & 1 & 2 \\
\hline & IV & 17 & $51.5 \%$ & 1 & 1 & 3 & 3 & 9 \\
\hline \multirow[t]{4}{*}{ Tumor size $(\mathrm{T})$} & $\mathrm{T} 1$ & 12 & $36.4 \%$ & 0 & 0 & 3 & 3 & 6 \\
\hline & $\mathrm{T} 2$ & 3 & $9 \%$ & 0 & 0 & 1 & 2 & 0 \\
\hline & T3 & 1 & $3 \%$ & 0 & 1 & 0 & 0 & 0 \\
\hline & $\mathrm{T} 4$ & 17 & $51.5 \%$ & 2 & 0 & 3 & 2 & 9 \\
\hline \multirow[t]{3}{*}{$\begin{array}{l}\text { Regional lymph } \\
\text { node status }(\mathrm{N})\end{array}$} & No & 18 & $54.4 \%$ & 2 & 0 & 5 & 3 & 9 \\
\hline & N1 & 5 & $15.2 \%$ & 0 & 0 & 1 & 3 & 1 \\
\hline & N2 & 10 & $30.3 \%$ & 0 & 1 & 1 & 1 & 7 \\
\hline \multirow{2}{*}{$\begin{array}{l}\text { Distant metastasis } \\
\text { status }(\mathrm{M})\end{array}$} & M0 & 33 & $100 \%$ & 2 & 1 & 7 & 7 & 16 \\
\hline & M1 & 0 & $0 \%$ & 0 & 0 & 0 & 0 & 0 \\
\hline
\end{tabular}

Based on the regional lymph node involvement ( $\mathrm{N}$ score) determined at histopathological evaluation, 18 cases (54.5\%) were N0, $5(15.2 \%)$ were N1, $10(30.3 \%)$ were N2 (in particular, 6 were N2a, 2 were N2b, and 2 were N2c. No cases showed distant metastases. At histopathological examination, six (18.1\%) cancers showed a moderate degree of differentiation (G2), whereas the remaining $27(81.8 \%)$ cases were well-differentiated cancers (G1).

The retromolar pad was very frequently involved ( $48.5 \%$ of cases) (Table 1); in addition, $24.2 \%$ of cases arose on the edentulous alveolar ridge. As a consequence, cancers located on the gingiva around teeth were only $27.2 \%$ of cases. In seven cases $(21.2 \%)$, there was also the involvement of the floor of the mouth. This always happened when the tumor was spreading from the mandibular edentulous alveolar ridge; in one case, the buccal mucosa adjacent to the involved retromolar pad was also involved. No multifocal lesions (i.e., synchronous second primary tumors) were registered.

A common presenting symptom was pain (11 patients-33.3\% of cases), sometimes ( 2 cases) associated with a burning sensation; in the remaining cases (22 patients-66.7\% of cases), cancer lesions were completely asymptomatic. Based on the data available for $17(51.5 \%)$ cases, a median of 50 days (range 2-300 days) passed from the moment when the patient became aware that something was ongoing (i.e., beginning of symptoms or observation of anatomic and/or color alterations) to the first medical consultation (patient delay). Counts of observed class of patient delay and the corresponding lesion's stage at the diagnosis are reported in Table 2 . A statistically significant association between patient delay and the cancer's stage was found $\left(\chi^{2}(9)=21.5, p=0.01\right)$ : the higher the patient delay, the higher was the cancer stage at the diagnosis. 
Table 2. Patient delay and OSCC stage at the diagnosis.

\begin{tabular}{|c|c|c|c|c|c|c|}
\hline \multirow[b]{2}{*}{ Stage } & \multirow[b]{2}{*}{ Cases } & \multicolumn{4}{|c|}{ Patient Delay Class } & \multirow[b]{2}{*}{ Total } \\
\hline & & 1 & 2 & 3 & 4 & \\
\hline \multirow[t]{3}{*}{1} & Observed & 0 & 3 & 0 & 2 & 5 \\
\hline & \% within row & $0.0 \%$ & $60.0 \%$ & $0.0 \%$ & $40.0 \%$ & $100.0 \%$ \\
\hline & $\%$ within column & $0.0 \%$ & $50.0 \%$ & $0.0 \%$ & $33.3 \%$ & $29.4 \%$ \\
\hline \multirow[t]{3}{*}{2} & Observed & 2 & 0 & 0 & 0 & 2 \\
\hline & \% within row & $100.0 \%$ & $0.0 \%$ & $0.0 \%$ & $0.0 \%$ & $100.0 \%$ \\
\hline & $\%$ within column & $100.0 \%$ & $0.0 \%$ & $0.0 \%$ & $0.0 \%$ & $11.8 \%$ \\
\hline \multirow[t]{3}{*}{3} & Observed & 0 & 1 & 1 & 0 & 2 \\
\hline & $\%$ within row & $0.0 \%$ & $50.0 \%$ & $50.0 \%$ & $0.0 \%$ & $100.0 \%$ \\
\hline & $\%$ within column & $0.0 \%$ & $16.7 \%$ & $33.3 \%$ & $0.0 \%$ & $11.8 \%$ \\
\hline \multirow[t]{3}{*}{4} & Observed & 0 & 2 & 2 & 4 & 8 \\
\hline & $\%$ within row & $0.0 \%$ & $25.0 \%$ & $25.0 \%$ & $50.0 \%$ & $100.0 \%$ \\
\hline & $\%$ within column & $0.0 \%$ & $33.3 \%$ & $66.7 \%$ & $66.7 \%$ & $47.1 \%$ \\
\hline \multirow[t]{3}{*}{ Total } & Observed & 2 & 6 & 3 & 6 & 17 \\
\hline & $\%$ within row & $11.8 \%$ & $35.3 \%$ & $17.6 \%$ & $35.3 \%$ & $100.0 \%$ \\
\hline & $\%$ within column & $100.0 \%$ & $100.0 \%$ & $100.0 \%$ & $100.0 \%$ & $100.0 \%$ \\
\hline
\end{tabular}

In general, at the time of diagnosis, oral cancer lesions exhibit different morphology with alterations in color and/or shape of the affected regions: data are collectively reported in Table 3, because no difference was found in relation to the location (i.e., gingiva, edentulous ridge, retromolar pad). The lesions were usually red (45.5\%), red and white $(45.4 \%)$, or white in a few other cases $(9.1 \%)$. The most prevalent morphology of the lesions was the ulcer $(69.7 \%)$, whereas exophytic masses $(12.1 \%)$ and flat lesions $(12.1 \%)$ were less frequent. The lesions had high consistence (ulcer borders were particularly firm and indurated) on palpation (except for one case of low consistence involving the pre-maxillary area); they were always firmly attached to contiguous tissues and were spontaneously bleeding in 10 patients $(30.3 \%)$.

Table 3. Clinical appearance of the investigated OSCC lesions.

\begin{tabular}{ccccc}
\hline \multirow{2}{*}{ Morphology } & \multicolumn{5}{c}{ Color } \\
\cline { 2 - 5 } & $\begin{array}{c}\text { Red } \\
\text { n. (\%) }\end{array}$ & $\begin{array}{c}\text { White } \\
\text { n. (\%) }\end{array}$ & $\begin{array}{c}\text { Red and White } \\
\text { n. (\%) }\end{array}$ & $\begin{array}{c}\text { Total } \\
\text { n. (\%) }\end{array}$ \\
\hline Flat lesion & $2(6 \%)$ & $2(6 \%)$ & 0 & $4(12.1 \%)$ \\
Ulcer & $10(30.3 \%)$ & 0 & $13(39.4 \%)$ & $23(69.7 \%)$ \\
Exophytic mass & $1(3 \%)$ & $1(3 \%)$ & $2(6 \%)$ & $4(12.1 \%)$ \\
Mixed lesion & $2(6 \%)$ & 0 & 0 & $2(6 \%)$ \\
Total & $15(45.5 \%)$ & $3(9.1 \%)$ & $14(45.4 \%)$ & $33(100 \%)$ \\
\hline
\end{tabular}

\section{Discussion}

Carcinomas of the gingiva and mucosa of the alveolar ridge are usually squamous cell carcinomas; although they are less common than those arising in oral cancer prone sites (e.g., the tongue and floor of the mouth [8]), their incidence may be very significant (up to 50\% [17]), especially in some populations of India [18]. Carcinoma of the gingiva generally arises in the premolar and molar regions and, more frequently, on the lower arch [19]. This preferential location in the lower jaw was confirmed in our series (91\% of cases), too. Unfortunately, more than half of the 33 cases included in the present study were advanced stage cancers (III and IV stage). We had a $51.5 \%$ of T4 cancers; other series reported an even higher frequency $(72.7 \%)$ of $\mathrm{T} 4$ cancers in the upper gingival-buccal complex [20]. Although this can be explained by anatomical reasons (i.e., close proximity to bone and other regions (floor of the mouth, maxillary sinus, infratemporal fossa)) that may facilitate local invasiveness [20-22], the time from initial presentation to diagnosis needs 
to be minimized. This requires both patient education and optimization of the diagnostic process.

Gingiva is susceptible to a wide spectrum of disorders $[23,24]$ including malignancy; since the diagnosis of oral cancer is mainly based on clinical oral examination, an adequate knowledge of its appearance, as well as of its precursors, is of utmost importance for a proper and early diagnosis. This is of particular relevance for practitioners dealing with prevention and management of other high incidence oral diseases (e.g., periodontal and dental diseases), because they have the possibility to periodically visit the patient for recall appointments and maintenance programs, thus being able to inspect gingiva and the whole oral cavity. Intraepithelial precursors of cancer [25], i.e., dysplasia and in situ carcinoma, may clinically manifest as alterations in color: a very common sign of potentially malignant lesions or early cancer (Figure 1A-D).

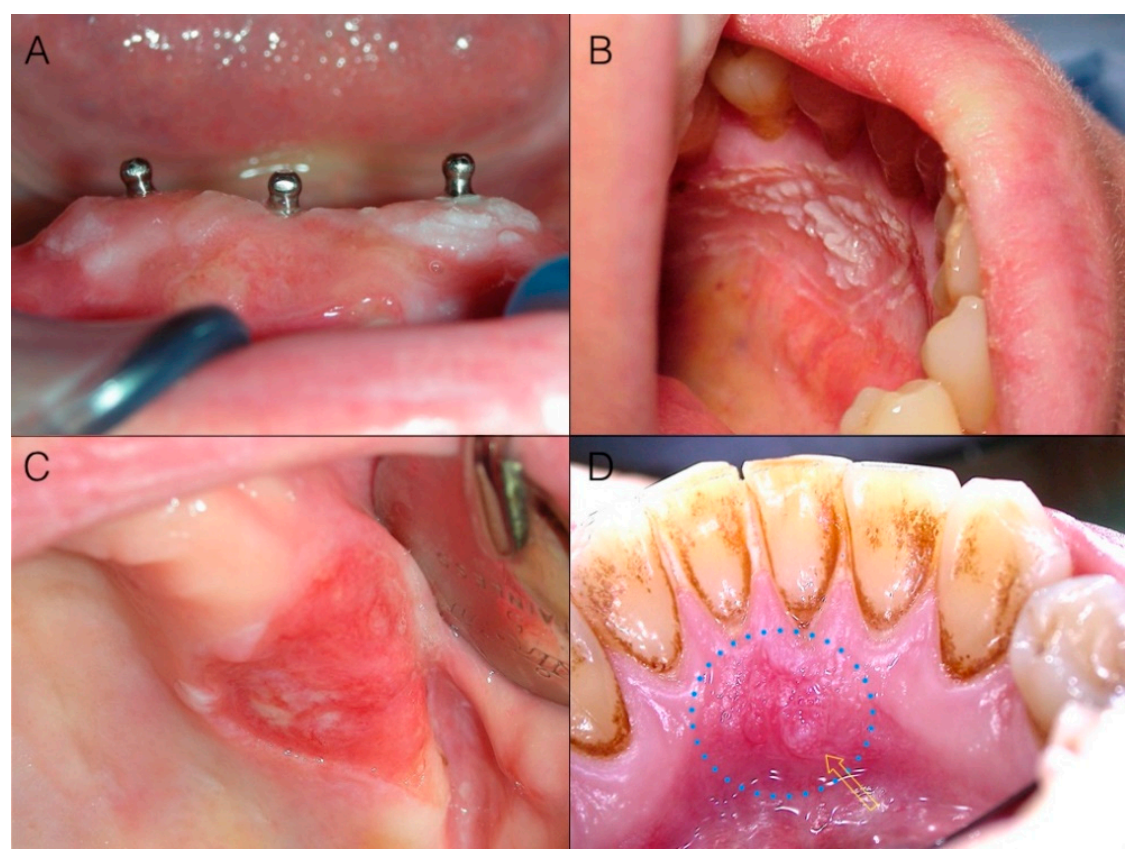

Figure 1. (A) Early gingival cancer appearing as a slightly elevated and non-homogeneous white lesion around implants; (B) Verrucous surface texture of early cancer around teeth: the lesion may be not immediately visible unless a cautious and thorough clinical oral examination (with adequate light conditions) is performed; (C) Gingival cancer appearing as a sharply defined red lesion of the maxillary tuberosity: sharp margins of a red lesion with a flat depressed surface topography deserve high suspicion; (D) Early gingival cancer appearing as a predominantly red lesion: note the loss of homogeneity (yellow arrow) both in color and surface texture.

Color alterations may include white (Figure 1A,B), red (Figure 1C,D), or white and red lesions (Figure 2A,D). In particular, reddish oral lesions (erythroplakia) are believed to be at higher risk of harboring intraepithelial neoplasia and/or early invasive carcinoma than whitish ones (homogeneous leukoplakia), and the development of reddish areas in the context of a white plaque (non-homogeneous or speckled leukoplakia) is considered a clinical sign of ongoing malignant transformation [26,27].

Invasion is characterized by alterations extending to underlying/contiguous tissues; thus, in addition to color, alterations in shape may occur. These involve, at first, the superficial macroscopic structure (Figure 2A,B), and then the bulk anatomy (Figure 2C,D), and encompass flat lesions, ulcers, exophytic masses, or often a combination of these. Ulcers are a very common appearance of gingival cancer, which accounted for $69.6 \%$ of our cases. Their shape is very variable (Figure 3 ) and can range from round/ovoid (Figure 3A), to linear (Figure 3B), to a very irregular shape (especially in advanced stages) (Figure 3C,D). In our series, an ovoid shape was very typical for malignant ulcers located on the maxillary 
tuberosity, while a linear shape was very frequent in the mandibular retromolar area, where OSCC always had an ulcerative morphology.

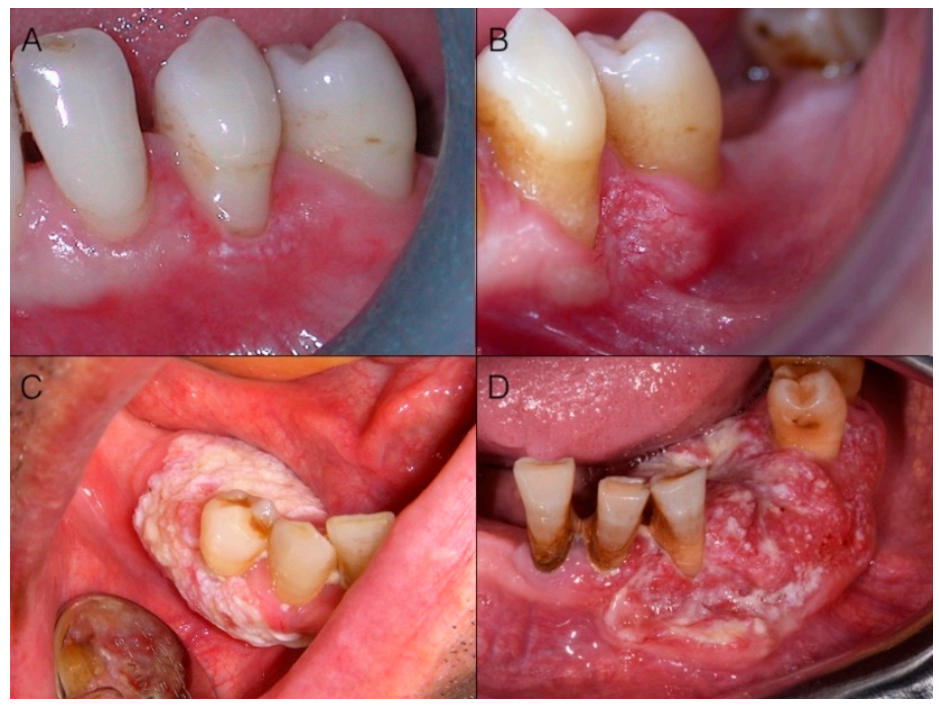

Figure 2. Alterations in color may "evolve" into alterations in shape during the progression of malignant transformation. (A) Red and white lesion: note the modifications in color of the attached gingiva of the tooth in the center of the picture in comparison with the adjacent teeth and the red and white appearance particularly evident at the gingival margin; (B) The same case three months later: the patient refused to have a biopsy done at the first evaluation visit. Note that alterations in shape are now present; the rolled up distal margin, the surface modifications in the central part of the lesion, and the aberrant vasculature are also evident. It is a T4a carcinoma invading through underlying bone; (C) Advanced white cancer of the gingiva: lack of homogeneity in color and surface, as well as margins irregularity, key features in evaluating suspected lesions, are evident; (D) Advanced cancer of the lower left gingiva with a speckled appearance. Note the mesial and vestibular rolled elevated margin, firm on palpation.

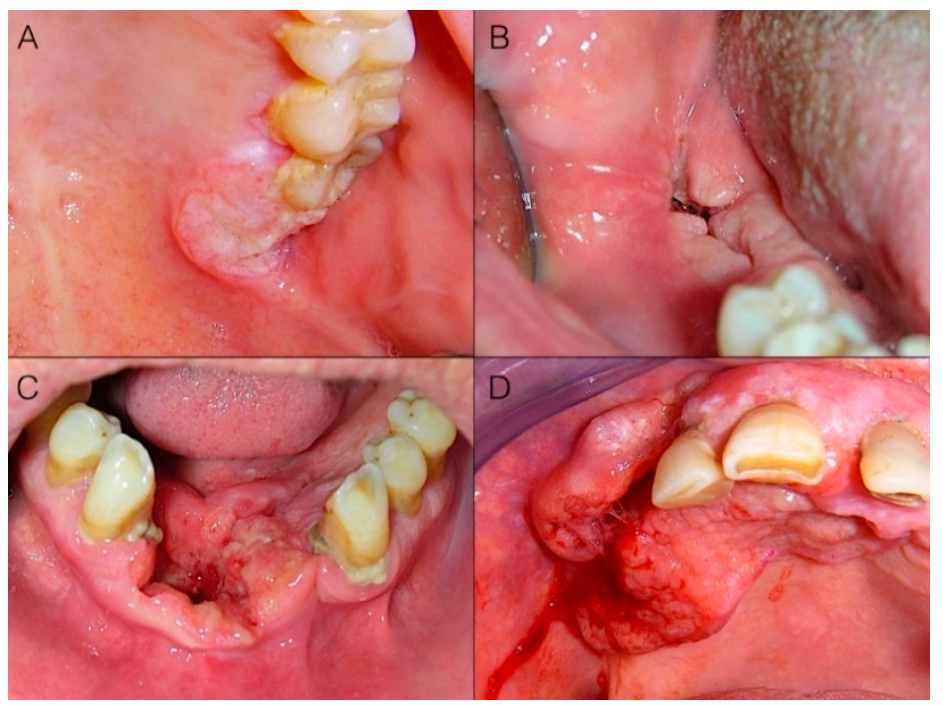

Figure 3. Different shapes of malignant ulcers on the gingiva. While the ulcer's base and margins deepen in the contiguous tissues, the superficial macroscopic structure is altered (A,B); then, bulk anatomy alterations (C,D) (due to both tissue loss at the base of the ulcer and margins' expansion/invasion), as well as bleeding (D) may occur. (A) Ovoid ulcer on the maxillary tuberosity. (B) Linear ulcer of the retromolar pad. (C) Irregular ulcer of the inferior alveolar ridge and floor of the mouth. (D) Irregular bleeding ulcer of the upper gingiva and alveolar ridge. 
In advanced stage cancers, the ulcer is often a component of an exophytic mass (Figure 4): i.e., an increase in volume of malignant tissue giving rise to a visible alteration in dimensions and proportions of the bulk anatomy of the involved region. Exophitic masses, accounting for $12.1 \%$ of our cases, presented no clinical diagnostic challenge at all.

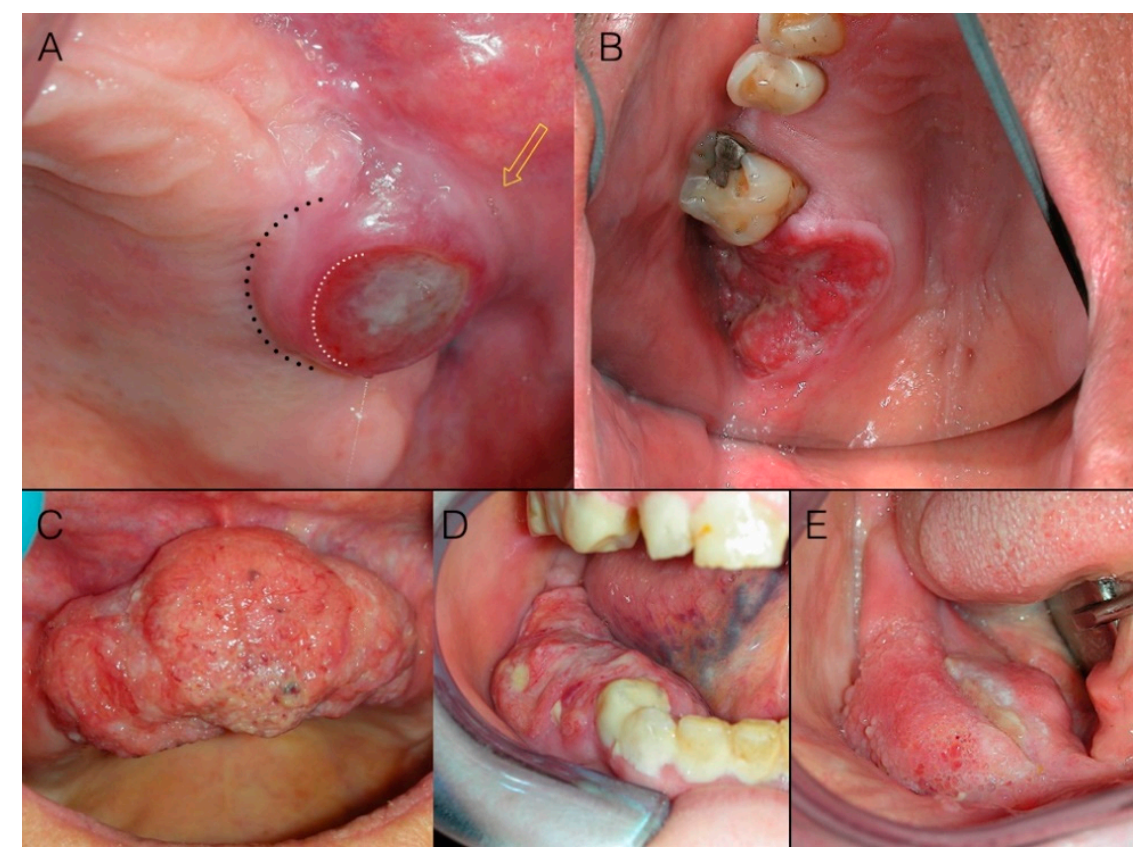

Figure 4. Margins of ulcers are the most informative portion of the lesion under a clinical diagnostic point of view. (A) Round malignant ulcer with firm, elevated borders. Note that limits (white dotted line) of the ulcer (i.e., loss of the epithelium) do not correspond to the margins (black dotted line) of the lesion (i.e., the clinical boundary of malignant infiltrating lesion), which is not precisely identifiable (yellow arrow); (B) Malignant ulcer with irregular shape, irregular surface, firm, elevated, and rolled up borders; (C) Squamous cell carcinoma of the gingiva appearing as an exophytic mass: note surface characteristics and aberrant vasculature, as well as irregularities in shape due to variable growth kinetic within the different areas of the tumor mass. Focal ulcerations (D,E) of masses, as well as alterations of the surface texture (E) are common.

\section{Conclusions}

Cancer on the gingiva is diagnosed, on average, at an advanced stage. The knowledge and understanding of its clinical features may be a cornerstone in improving its early diagnosis. Information to the patient and the attention of oral health care providers should be driven on potential suspected lesions. Color alterations may include white, red, or mixed lesions; alterations in shape may involve both the superficial macroscopic structure and the bulk anatomy, and encompass flat lesions, ulcers, or exophytic masses. A careful clinical evaluation of surface and margins of such lesions offers valuable diagnostic insights.

Author Contributions: Conceptualization, L.L.R. and G.C. (Giuseppina Campisi); methodology, G.C. (Giuseppe Colella); writing-original draft preparation, L.L.R. and V.P.; writing-review and editing, E.L.M. and M.E.B.; supervision, L.L.M. All authors have read and agreed to the published version of the manuscript.

Funding: This research received no external funding.

Institutional Review Board Statement: Ethical review and approval were waived for this study due to the fact that it was a retrospective study on archived data.

Informed Consent Statement: Once retrieved from clinical notes, data were anonymized and then analyzed for statistical purposes. Patients consent for such analysis was obtained. 
Conflicts of Interest: The authors declare no conflict of interest.

\section{References}

1. Ferlay, J.; Colombet, M.; Soerjomataram, I.; Mathers, C.; Parkin, D.M.; Pineros, M.; Znaor, A.; Bray, F. Estimating the global cancer incidence and mortality in 2018: GLOBOCAN sources and methods. Int. J. Cancer 2019, 144, 1941-1953. [CrossRef]

2. Ferlay, J.; Soerjomataram, I.; Dikshit, R.; Eser, S.; Mathers, C.; Rebelo, M.; Parkin, D.M.; Forman, D.; Bray, F. Cancer incidence and mortality worldwide: Sources, methods and major patterns in GLOBOCAN 2012. Int. J. Cancer 2015, 136, E359-E386. [CrossRef]

3. Shield, K.D.; Ferlay, J.; Jemal, A.; Sankaranarayanan, R.; Chaturvedi, A.K.; Bray, F.; Soerjomataram, I. The global incidence of lip, oral cavity, and pharyngeal cancers by subsite in 2012. CA Cancer J. Clin. 2017, 67, 51-64. [CrossRef] [PubMed]

4. van Monsjou, H.S.; Wreesmann, V.B.; van den Brekel, M.W.; Balm, A.J. Head and neck squamous cell carcinoma in young patients. Oral Oncol. 2013, 49, 1097-1102. [CrossRef] [PubMed]

5. De Angelis, R.; Sant, M.; Coleman, M.P.; Francisci, S.; Baili, P.; Pierannunzio, D.; Trama, A.; Visser, O.; Brenner, H.; Ardanaz, E.; et al. Cancer survival in Europe 1999-2007 by country and age: Results of EUROCARE-5-a population-based study. Lancet Oncol. 2014, 15, 23-34. [CrossRef]

6. Seoane, J.; Alvarez-Novoa, P.; Gomez, I.; Takkouche, B.; Diz, P.; Warnakulasiruya, S.; Seoane-Romero, J.M.; Varela-Centelles, P. Early oral cancer diagnosis: The Aarhus statement perspective. A systematic review and meta-analysis. Head Neck 2016, 38 (Suppl. 1), E2182-E2189. [CrossRef]

7. McGurk, M.; Chan, C.; Jones, J.; O’Regan, E.; Sherriff, M. Delay in diagnosis and its effect on outcome in head and neck cancer. Br. J. Oral Maxillofac. Surg. 2005, 43, 281-284. [CrossRef]

8. Barasch, A.; Gofa, A.; Krutchkoff, D.J.; Eisenberg, E. Squamous cell carcinoma of the gingiva. A case series analysis. Oral Surg. Oral Med. Oral Pathol. Oral Radiol. Endod. 1995, 80, 183-187. [CrossRef]

9. $\quad$ Eicher, S.A.; Overholt, S.M.; el-Naggar, A.K.; Byers, R.M.; Weber, R.S. Lower gingival carcinoma. Clinical and pathologic determinants of regional metastases. Arch. Otolaryngol. Head Neck Surg. 1996, 122, 634-638. [CrossRef]

10. Makridis, S.D.; Mellado, J.R.; Freedman, A.L.; Salkin, L.M.; Stein, M.D.; Leal, K.; Miller, A.S. Squamous cell carcinoma of gingiva and edentulous alveolar ridge: A clinicopathologic study. Int. J. Periodontics Restor. Dent. 1998, 18, $292-298$.

11. Koduganti, R.R.; Sehrawat, S.; Reddy, P.V. Gingival squamous cell carcinoma: A diagnostic impediment. J. Indian Soc. Periodontol. 2012, 16, 104-107. [CrossRef]

12. Lee, J.J.; Cheng, S.J.; Lin, S.K.; Chiang, C.P.; Yu, C.H.; Kok, S.H. Gingival squamous cell carcinoma mimicking a dentoalveolar abscess: Report of a case. J. Endod. 2007, 33, 177-180. [CrossRef]

13. Levi, P.A., Jr.; Kim, D.M.; Harsfield, S.L.; Jacobson, E.R. Squamous cell carcinoma presenting as an endodontic-periodontic lesion. J. Periodontol. 2005, 76, 1798-1804. [CrossRef]

14. Kirkham, D.B.; Hoge, H.W.; Sadeghi, E.M. Gingival squamous cell carcinoma appearing as a benign lesion: Report of case. J. Am. Dent. Assoc. 1985, 111, 767-769. [CrossRef]

15. Yoon, T.Y.; Bhattacharyya, I.; Katz, J.; Towle, H.J.; Islam, M.N. Squamous cell carcinoma of the gingiva presenting as localized periodontal disease. Quintessence Int. 2007, 38, 97-102.

16. Lydiatt, W.M.; Patel, S.G.; O'Sullivan, B.; Brandwein, M.S.; Ridge, J.A.; Migliacci, J.C.; Loomis, A.M.; Shah, J.P. Head and Neck cancers-major changes in the American Joint Committee on cancer eighth edition cancer staging manual. CA Cancer J. Clin. 2017. [CrossRef]

17. Jainkittivong, A.; Swasdison, S.; Thangpisityotin, M.; Langlais, R.P. Oral squamous cell carcinoma: A clinicopathological study of 342 Thai cases. J. Contemp. Dent. Pract. 2009, 10, E033-E040.

18. Mehrotra, R.; Singh, M.; Kumar, D.; Pandey, A.N.; Gupta, R.K.; Sinha, U.S. Age specific incidence rate and pathological spectrum of oral cancer in Allahabad. Indian J. Med. Sci. 2003, 57, 400-404. [PubMed]

19. Fitzpatrick, S.G.; Neuman, A.N.; Cohen, D.M.; Bhattacharyya, I. The clinical and histologic presentation of gingival squamous cell carcinoma: A study of 519 cases. Oral Surg. Oral Med. Oral Pathol. Oral Radiol. 2012, 114, 509-515. [CrossRef] [PubMed]

20. Pathak, K.A.; Mathur, N.; Talole, S.; Deshpande, M.S.; Chaturvedi, P.; Pai, P.S.; Chaukar, D.A.; D'Cruz, A.K. Squamous cell carcinoma of the superior gingival-buccal complex. Oral Oncol. 2007, 43, 774-779. [CrossRef] [PubMed]

21. Wang, T.C.; Hua, C.H.; Lin, C.C.; Tsou, Y.A.; Tseng, H.C.; Tsai, M.H. Risk factors affect the survival outcome of hard palatal and maxillary alveolus squamous cell carcinoma: 10-year review in a tertiary referral center. Oral Surg. Oral Med. Oral Pathol. Oral Radiol. Endod. 2010, 110, 11-17. [CrossRef]

22. Beltramini, G.A.; Massarelli, O.; Demarchi, M.; Copelli, C.; Cassoni, A.; Valentini, V.; Tullio, A.; Gianni, A.B.; Sesenna, E.; Baj, A. Is neck dissection needed in squamous-cell carcinoma of the maxillary gingiva, alveolus, and hard palate? A multicentre Italian study of 65 cases and literature review. Oral Oncol. 2012, 48, 97-101. [CrossRef]

23. Lo Russo, L.; Guiglia, R.; Pizzo, G.; Fierro, G.; Ciavarella, D.; Lo Muzio, L.; Campisi, G. Effect of desquamative gingivitis on periodontal status: A pilot study. Oral Dis. 2010, 16, 102-107. [CrossRef] [PubMed]

24. Lo Russo, L.; Fedele, S.; Guiglia, R.; Ciavarella, D.; Lo Muzio, L.; Gallo, P.; Di Liberto, C.; Campisi, G. Diagnostic pathways and clinical significance of desquamative gingivitis. J. Periodontol. 2008, 79, 4-24. [CrossRef]

25. Gale, N.; Pilch, B.Z.; Sidransky, D.; El Naggar, A.; Westra, W.; Califano, J.; Johnson, N.; MacDonald, D.G. Tumors of the oral cavity and oropharynx. In World Health Organization Classification of Tumors: Pathology E Genetics of Head and Neck Tumors; Barnes, L., Eveson, J.W., Reichart, P., Sidransky, D., Eds.; IARC Press: Lyon, French, 2005; pp. 177-179. 
26. Fedele, S.; Lo Russo, L.; Mignogna, C.; Staibano, S.; Porter, S.R.; Mignogna, M.D. Macroscopic classification of superficial neoplastic lesions of the oral mucosa: A preliminary study. Eur. J. Surg. Oncol. 2008, 34, 100-106. [CrossRef] [PubMed]

27. Mignogna, M.D.; Fedele, S.; Lo Russo, L. Dysplasia/neoplasia surveillance in oral lichen planus patients: A description of clinical criteria adopted at a single centre and their impact on prognosis. Oral Oncol. 2006, 42, 819-824. [CrossRef] [PubMed] 